\title{
Methodology Report \\ Employment of Oligodeoxynucleotide plus Interleukin-2 Improves Cytogenetic Analysis in Splenic Marginal Zone Lymphoma
}

\author{
Antonella Bardi, ${ }^{1}$ Francesco Cavazzini, ${ }^{1}$ Gian Matteo Rigolin, ${ }^{1}$ Elisa Tammiso, ${ }^{1}$ \\ Eleonora Volta, ${ }^{1}$ Elisa Pezzolo, ${ }^{1}$ Luca Formigaro, ${ }^{1}$ Olga Sofritti, ${ }^{1}$ Giulia Daghia, ${ }^{1}$ \\ Cristina Ambrosio, ${ }^{1}$ Lara Rizzotto, ${ }^{1}$ Awad E. Abass, ${ }^{1}$ Fiorella D'Auria, ${ }^{2}$ \\ Pellegrino Musto, ${ }^{2}$ and Antonio Cuneo ${ }^{1}$ \\ ${ }^{1}$ Section of Haematology, Department of Bio-Medical Sciences and Advanced Therapies, University of Ferrara, Ferrara, Italy \\ ${ }^{2}$ Department of Onco-Hematology, IRCCS, Centro di Riferimento Oncologico della Basilicata, Via Padre Pio 1, \\ 85028 Rionero in Vulture (Pz), Italy \\ Correspondence should be addressed to Pellegrino Musto,p.musto@tin.it
}

Received 16 October 2010; Revised 21 February 2011; Accepted 15 March 2011

Academic Editor: Anita M. Oberbauer

Copyright (๑) 2011 Antonella Bardi et al. This is an open access article distributed under the Creative Commons Attribution License, which permits unrestricted use, distribution, and reproduction in any medium, provided the original work is properly cited.

\begin{abstract}
To compare the efficiency of novel mitogenic agents and traditional mitosis inductors, 18 patients with splenic marginal zone lymphoma (SMZL) were studied. Three cultures using oligodeoxynucleotide (ODN) plus interleukin-2 (IL-2), or TPA, or LPS were setup in each patient. Seventeen/18 cases with ODN + IL2 had moderate/good proliferation $(94,4 \%)$ as compared with $10 / 18$ cases with TPA and LPS $(55 \%)(P=.015) ; 14 / 18(77,7 \%)$ cases with ODN + IL2 had sufficient good quality of banding as compared with $8 / 18$ cases $(44,4 \%)$ with TPA and LPS. The karyotype could be defined from ODN + IL2-stimulated cultures in all 18 patients, 14 of whom $(77,7 \%)$ had a cytogenetic aberration, whereas clonal aberrations could be documented in 9 and in 3 cases by stimulation with LPS and TPA, respectively. Recurrent chromosome aberrations in our series were represented by aberrations of chromosome 14q in 5 patients, by trisomy 12 and $7 \mathrm{q}$ deletion in 4 cases each, and by abnormalities involving $11 \mathrm{q}$ and $13 \mathrm{q}$ in two cases each. These findings show that stimulation with ODN + IL2 offers more mitotic figures of better quality and results in an increased rate of clonal aberrations in SMZL, making this method ideal for prospective studies aiming at the definition of the prognostic impact of cytogenetic aberrations in this disorder.
\end{abstract}

\section{Introduction}

Splenic marginal zone lymphoma (SMZL) is an indolent disease, representing $<2 \%$ of the lymphoid neoplasms, which was recognized as separate clinicopathological entity in the World Health Organization 2008 (WHO) classification [1]. Studies using conventional cytogenetic analysis and molecular cytogenetic techniques disclosed a number of recurrent chromosome and genetic lesions in this disorder [2]. Due to low spontaneous mitotic activity, stimulation using 12-O-tetradecanoylphorbol 12-myristate 13-acetate (TPA), or a combination of TPA and lipopolysaccharide (LPS) in parallel cultures, was employed in previous studies
[3-8] revealing abnormal karyotypes in $43-72 \%$ of the cases $[5,9]$. Indeed, the combination of data derived from conventional cytogenetic analysis, along with data derived from the application of fluorescence in situ hybridization (FISH) and comparative genomic hybridization (CGH) [10, 11], allowed for the definition of a cytogenetic profile of SMZL. Deletion of the long arm of chromosome 7 is regarded as the most characteristic anomaly of SMZL [12]; other recurrent aberrations are represented by total/partial trisomy $3 \mathrm{q}$ in $20-40 \%$ of the cases and by $14 \mathrm{q} 32 / \operatorname{IgH}$ translocations, $+12,17 \mathrm{p} /$ TP53 deletion, $6 \mathrm{q}-,+12$, and +18 in $5-10 \%$ of the cases, as documented in a recent large multicentre study using the traditional TPA mitogen stimulation [13]. 
Because conventional karyotype analysis is the only method allowing for the visualization in a single experiment of any type of chromosomal defect, including gains, losses, and balanced translocations, attention was recently devoted to the development of efficient mitogenic stimulation. In chronic lymphocytic leukemia (CLL), the introduction of stimulation by CpG oligodeoxynucleotide (ODN-DSP30) combined with IL2 allowed for the identification of more cases with clonal aberrations than in previous analyses using other mitogens and showed that a fraction of cases with apparently normal FISH results may carry chromosome lesions in regions not covered by conventional probe panels $[14,15]$. Because the identification of an optimal mitogen stimulation can be expected to reduce the rate of normal results in low-grade lymphoproliferative disorder, we designed this study which aimed at analyzing the impact of the innovative combination of immunostimulatory ODN + IL2 in cell culture in 18 cases of well-documented SMZL.

\section{Design and Methods}

2.1. Patients and Samples. Eighteen cases of SMZL seen at our Institution between 2008 and June 2010 were included in the present analysis (Table 1). All the patients were studied by cytogenetic analysis as part of diagnostic workup. Samples from 13 patients were obtained at disease presentation, whereas 5 patients were sent for cytogenetic analysis 5-12 months after initial presentation.

Diagnosis was made according to the WHO [1] histopathologic criteria in one patient in whom splenectomy was performed for diagnostic purposes; in the remaining 17 patients, diagnosis was based on the combination of presentation features, morphologic and immunologic features, and bone marrow findings [16]. Minimal requirements were represented by (a) peripheral and bone marrow lymphocytosis (i.e., $>5 \times 10^{9} / \mathrm{L}$ B-lymphocytes in the $\mathrm{PB}$ and/or $>40 \%$ lymphocytes in the BM aspiration or lymphoid infiltrate on biopsy sections), with or without splenomegaly and minimal adenopathy, (b) morphology consistent with SMZL (i.e., small-to-medium-sized lymphocytes, with or without villous lymphocytes and/or plasmacytoid features, and (c) immunophenotype consistent with chronic B-cell proliferation with a Matutes score $\leq 3$ [17].

2.2. Conventional Cytogenetic Analysis. Conventional cytogenetic analysis was performed on cells obtained from peripheral blood $(\mathrm{PB})$ in 14 cases, from $\mathrm{BM}$ aspirate in 3 cases, and from a spleen sample in 1 case (Table 2). Methods for cytogenetic analysis used in our laboratories were previously published [18]. Spleen samples were minced with a scalpel to obtain a single cell suspension. After separation by centrifugation over Ficoll-Hypaque, PB, BM, and splenic cells were cultured for $72 \mathrm{~h}$ in $10 \mathrm{ml}$ RPMI 1640 (Gibco-Invitrogen) supplemented with $20 \%$ fetal calf serum (FCS-GibcoInvitro-gen), $2 \mathrm{mmol} / \mathrm{L}$ GlutaMAX (Gibco-Invitro-gen), $100 \mathrm{U} / \mathrm{mL}$ penicillin, and $100 \mu \mathrm{g} / \mathrm{mL}$ streptomycin (GibcoInvitrogen). Three separate cell cultures were setup in all patients, using the 3 different mitogens: (i) 12-O-tetradecanoylphorbol 12 -myristate 13 -acetate (TPA; $50 \mathrm{ng} / \mathrm{mL}-$
TABLE 1: Clinical features at presentation in 18 cases of SMZL.

\begin{tabular}{lc}
\hline Median age, $y$ (range) & $74(56-85)$ \\
Sex, male/female & $13 / 5$ \\
Splenomegaly yes/no & $11 / 7$ \\
Lymphadenopathy $($ yes/no) & $1 / 14$ \\
$>40 \%$ lymphs in the BM aspirate & $11 / 4$ \\
Lymphocytosis $\geq 5 \times 10^{9} / \mathrm{L}$ yes/no & $11 / 7$ \\
Absolute lymphocyte count $\left(\times 10^{9} / \mathrm{L}\right)$ & $0.68-31.49$ \\
Villous lymphocytes yes/no & $($ median 6,63$)$ \\
Hb $<12$ g/dL yes/no & $6 / 9$ \\
& $5 / 13$ \\
Platelet count $\leq 100 \times 10^{9} / \mathrm{L}$ yes/no & $(8.6-15.2)$ \\
CD5 expression yes/no & $4 / 14$ \\
\hline
\end{tabular}

Sigma-Aldrich), (ii) lipopolysaccharide (LPS; $40 \mu \mathrm{g} / \mathrm{mL}-$ Sigma-Aldrich), and (iii) immunostimulatory CpG-oligonucleotide DSP30 plus IL2 $(2 \mu \mathrm{mol} / \mathrm{L}$ GpC-ODN-TCGTCGCTGTCTCCGCTTCTTCTTGCC) (TibMolBiol, Berlin, Germany/IL2 $100 \mathrm{U} / \mathrm{mL}$ Stem Cell Technologies Inc) according to the method described by Dicker et al. [14]. Whenever possible, an additional $72 \mathrm{~h}$ unstimulated control culture was setup (6 cases). All cultures were setup with a cell concentration of $2 \times 10^{6} / \mathrm{mL}$ and incubated at $37^{\circ} \mathrm{C}$ in a $5 \% \mathrm{CO}_{2}$ fully humidified atmosphere under standard conditions which have remained unchanged at our laboratories during the study period. Colcemid (Kario Max Colcemid Solution 0,05 $\mu \mathrm{g} / \mathrm{mL}$ Gibco, Invitrogen) was added for four hours before harvest. Harvesting and slide preparation were performed by the same technician (ET) throughout the study period using hypotonic treatment (20 minutes incubation in $0,075 \mathrm{~mol} / \mathrm{L}$ potassium chloride); a classical 3:1 methanol/acetic acid solution was used as fixative. Slides were prepared using a predetermined volume (i.e., $20 \mu \mathrm{l}$ ) of fixed cell suspension, and metaphases were G-banded with Wright's stain [19]. Whenever possible, 20 or more metaphases were analyzed from each culture, and karyotypes were described according to the International System for Human Cytogenetics Nomenclature (ISCN 2005) [20]. Complex karyotype was defined by the presence of 3 or more cytogenetic aberrations in the same clone. To compare the efficiency of the 3 different mitogens, the following cytogenetic features were assessed in the different culture types by visualization at the microscope of the metaphases present on one slide.

(a) Proliferation. Based on the number of mitotic figures, the following score was adopted.

Score 1: failure, defined by the presence of 0-1 mitotic figures.

Score 2: poor proliferation, defined by the presence of $2-10$ mitotic figures.

Score 3: moderate proliferation, defined by the presence of 1119 mitotic figures.

Score 4: good proliferation, defined by the presence of $\geq 20$ mitotic figures. 


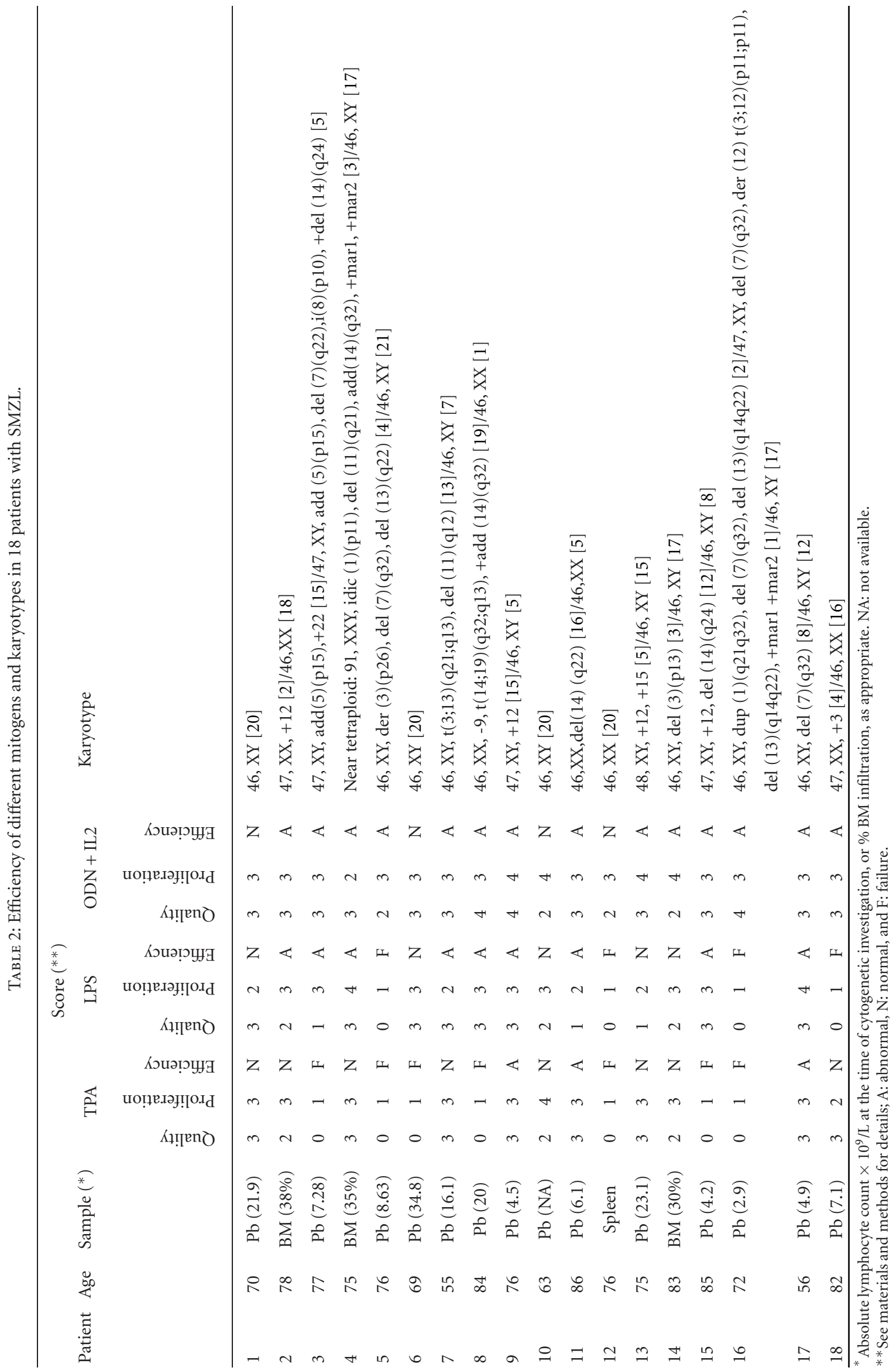


(b) Quality of Banding. The number of chromosomal bands per haploid set of chromosomes was counted referring to the ideograms of banding patterns present in the guidelines of ISCN 2005 [20]. The following score was adopted.

Score 1: insufficient quality for karyotyping $(<100$ visible chromosome bands).

Score 2: poor quality (<200 visible chromosome bands).

Score 3: sufficient quality (200-300 visible chromosome bands).

Score 4: good quality (>300 visible chromosome bands).

(c) Stimulation Efficiency. The number of metaphases with clonal abnormalities in each culture system was evaluated, and the karyotypes were divided in three groups:.

Score 1: failure, less than 10 analyzable metaphases.

Score 2: normal, absence of clonal abnormalities.

Score 3: abnormal I, karyotype with clonal chromosomal abnormalities, that is, the same structural rearrangement or chromosome gain in at least two mitotic figures, or chromosome loss in at least three mitoses.

\section{Results}

3.1. Hematologic and Clinical Features. All 18 patients had an unequivocal diagnosis of SMZL with PB and/or BM involvement by a clonal expansion of B-lymphocytes consistent with a marginal zone phenotype as assessed by immunophenotyping. The patients had 2,9-34,8 $\times 10^{9} / \mathrm{L}$ PB lymphocytes at time of sampling for cytogenetic analysis, and no patient had cytologic and/or histologic features suggestive of transformation into high-grade lymphoma. BM involvement with $>40 \%$ lymphocytes was detected in $11 / 15$ cases, splenomegaly was present in $11 / 18$ cases. A minority of patients had anemia or thrombocytopenia. Demographics and hematologic data in our patients are presented in Table 1.

3.2. Outcome of Cytogenetic Investigations. The karyotype could be defined in all 18 cases. No analyzable mitoses were obtained from $72 \mathrm{~h}$ unstimulated parallel culture in 6 cases. The outcome of cytogenetic investigations using different mitogens is shown in Figures 1-5.

3.3. Proliferation. Proliferation with at least 1 mitogen was assessable in all 18 cases. The number of cases with failure, low, moderate, and good proliferation is shown in Figure 1. More cases with score 3-4 were seen in ODN + IL2stimulated cultures ( 17 cases $=94,4 \%$ ) as compared with TPA and LPS (10 cases each; 55,5\%) $(P=.015)$.

Seven/18 patients $(38,8 \%)$ with TPA and $4 / 18$ patients $(22,2 \%)$ with LPS had score 1 (failure), whereas no failure was observed in ODN + IL2-stimulated culture.

3.4. Quality of Banding. The quality of banding expressed as number of bands in mitotic figures from the different cell cultures is shown in Figure 2. A good quality of banding

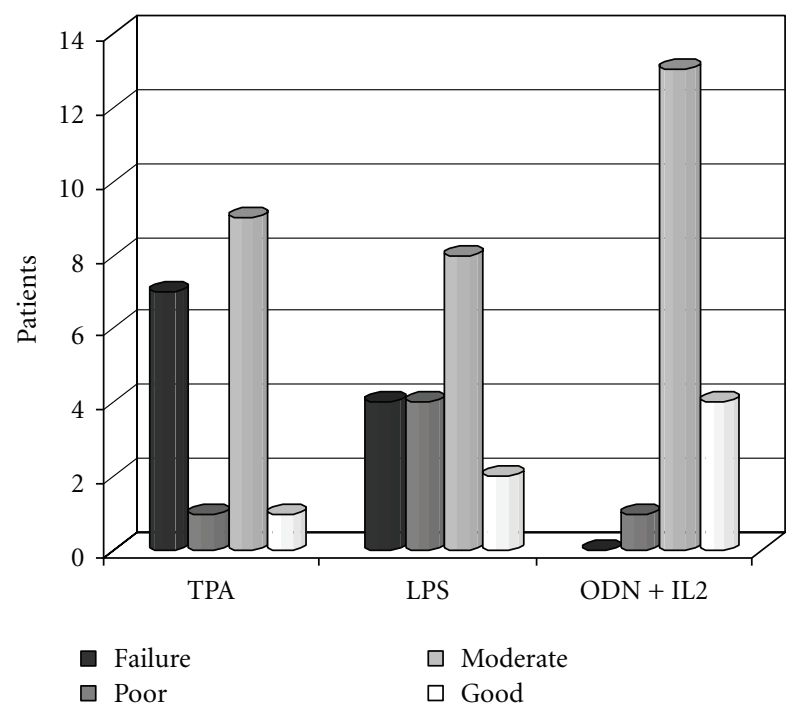

FIGURE 1: No. of patients with failure, poor, moderate, and good proliferation following stimulation by different mitogens.

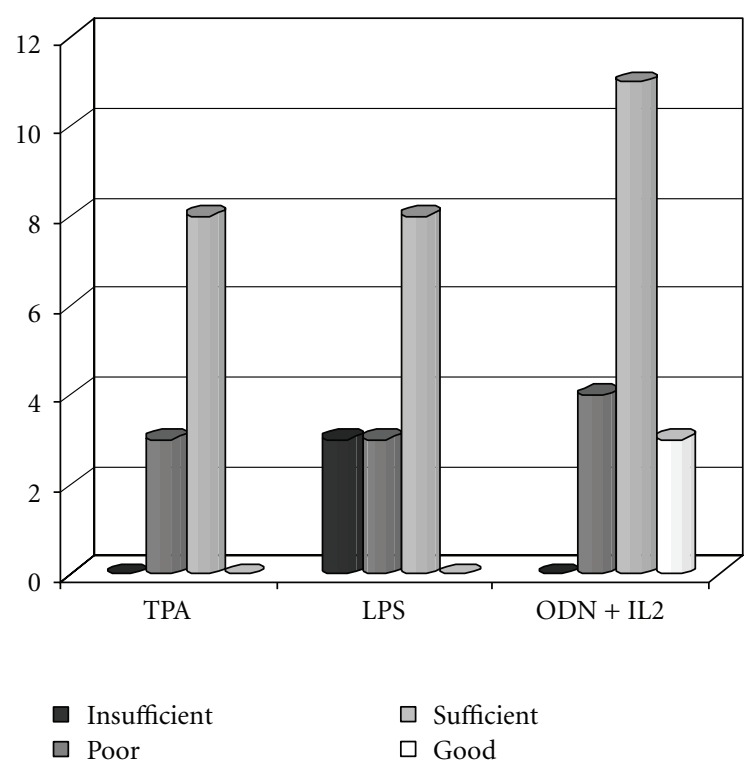

FIGURE 2: Quality of banding: black-coloured column corresponds to insufficient chromosome quality, grey-coloured column corresponds to poor quality, light grey and white correspond to sufficient and good quality, respectively, in every stimulation procedure.

(score 4) was observed in 3/18 cases with ODN + IL2 and in no case with TPA or LPS. Overall, 14/18 cases with ODN + IL2 had score 3-4 (77,7\%) as compared with $8 / 18$ cases $(44,4 \%)$ with TPA and LPS $(P=.067)$. An example of the quality of chromosome banding is shown in Figure 3.

3.5. Stimulation Efficiency. The karyotypes are described in Table 2, along with outcome measures (i.e., quality of banding and proliferation score) using different mitogens. The karyotype could be defined from ODN + IL2-stimulated 


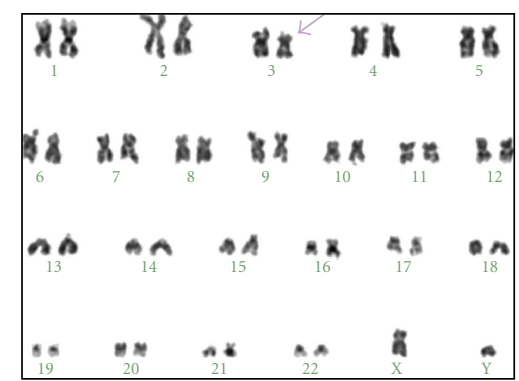

(a)

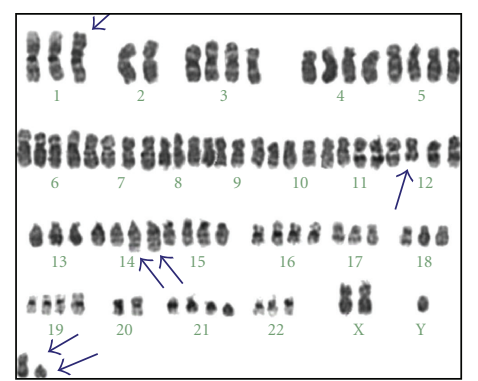

(b)

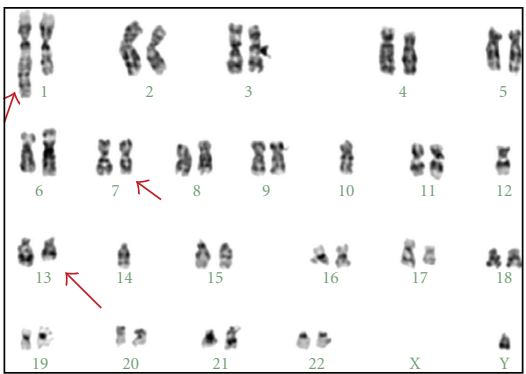

(c)

Figure 3: G-banding karyotypes showing some examples of poor quality (score2-(a), patient 14), sufficient quality (score3-(b), patient 4), and good quality (score4-(c), patient 16).

cultures in all 18 patients, 14 of whom $(77,7 \%)$ had a cytogenetic aberration.

Clonal aberrations could be documented in 9 cases $(50 \%)$ and in 3 cases $(16,6 \%)$ by stimulation with LPS and TPA, respectively, whereas in the remaining cases, normal karyotype or failure was observed with these mitogens as shown in Figure 4.

Five patients had a complex karyotype (pat. 3, 4, 5, 8, and 16 in Table 2), with numerical gains and structural abnormalities. One case was in the near-tetraploid range (pat. 4). The most frequent abnormalities (see Figure 5) were represented by aberrations of chromosome $14 \mathrm{q}$ in 5 patients, 3 of whom had a 14q interstitial deletion (nos. 3, 11, and 15). In patient 8 a t $(14 ; 19)(\mathrm{q} 32 ; \mathrm{q} 13)$ translocation was detected. Trisomy 12 and $7 \mathrm{q}$ deletion were observed in 4 cases each. Abnormalities involving 11q and $13 \mathrm{q}$ were observed in two cases each.

\section{Discussion}

Cytogenetic analysis has an established role in the diagnostic workup [21] and risk assessment of chronic lymphoproliferative disorders $[13,22,23]$. Because the mitotic index in these indolent disorders is low, stimulation with LPS and TP was widely employed $[3,24]$. Evidence was recently provided that conventional karyotyping may allow for the detection of aberrations, especially translocations, not detectable by molecular cytogenetic methods [25] and that ODN + IL2 stimulation may disclose more cytogenetically abnormal cases than was previously thought in CLL $[14,26]$. In particular, in a CLL Research Consortium study, more clonal abnormalities were observed after culture of CLL cells with ODN than with the traditional pokeweed mitogen (PWM) plus TPA [27]. All clonal abnormalities in PWM + TPA cultures were observed in ODN cultures, whereas ODN identified some clones not found by PWM + TPA. These results were reproducible in five different laboratories, and all abnormalities were concordant with FISH.

In this study, we were able to show that improved mitotic stimulation can be obtained in SMZL, a lowgrade lymphoproliferative disorder, by using ODN + IL2 in analogy with CLL. Indeed, a significantly greater number of mitotic figures could be observed in ODN + IL2-stimulated

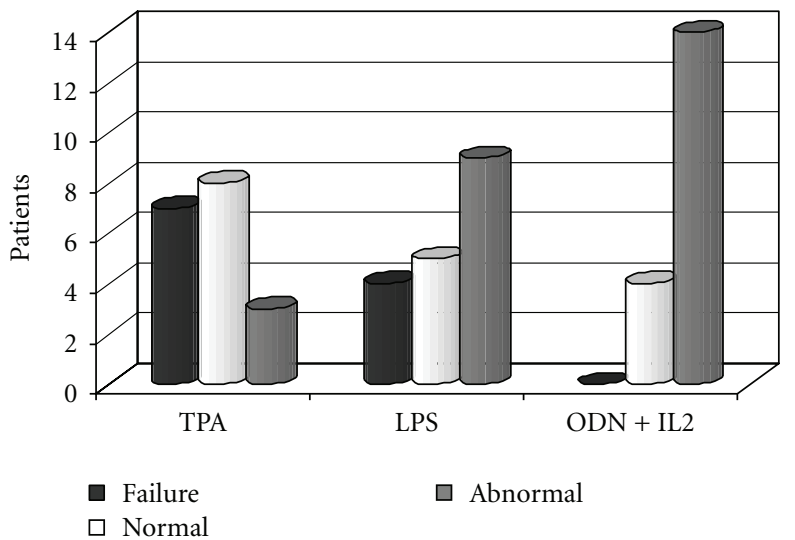

FIGURE 4: Stimulation efficiency: grey colour column represents abnormal cells, and dark and white colour columns represent failure and normal, respectively, in every stimulation procedure.

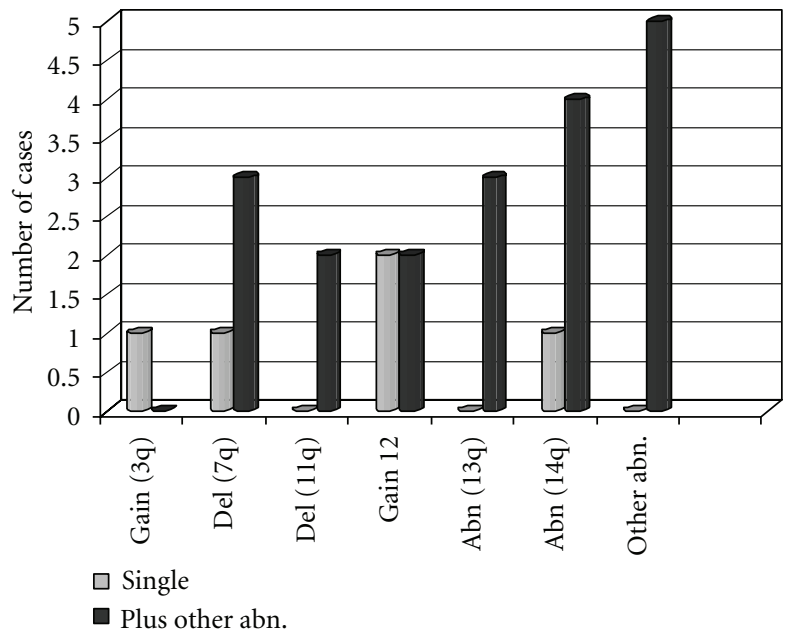

FIGURE 5: Total clonal chromosome abnormalities: distribution of recurrent abnormalities if they were found as single aberration or in association with other abnormalities.

cultures, which offered chromosomes of better quality with more clonal aberrations with respect to TPA/LPS-stimulated cultures. The karyotype could be defined in 100\% of 
ODN + IL2-stimulated cultures, $77,7 \%$ of which showed a clonal abnormality, as compared with 50\% karyotypically abnormal cases obtained by a combination of results from LPS/TPA-stimulated cultures in the same patients. The percentage of cytogenetically abnormal cases in LPS/TPAstimulated cultures was in line with previous reports [5, $9,13]$. It is worth noting that at the time of sampling for cytogenetic analysis the majority of our patients were at an initial stage of the disease with moderate lymphocytosis and splenomegaly, no lymph node involvement, and absence of anemia or thrombocytopenia in the majority of them. Interestingly, the capability to detect abnormal clones was independent of the degree of lymphocytosis and BM involvement, since all cases with $<5 \times 10^{9} / \mathrm{L}$ lymphocytes in the $\mathrm{PB}$ and with $<40 \%$ BM lymphocytes could be shown to have an abnormal karyotype (Table 2).

Thus, our data demonstrate that ODN + IL2 is the method of choice to enhance cell divisions of good quality for karyotyping in SMZL, in keeping with a recent analysis documenting a 97\% rate of aberrant karyotypes in 29 SMZL [28].

The cytogenetic profile in our patients confirms that $7 \mathrm{q}$ deletion, $3 \mathrm{q}$ abnormalities, +12 , and $14 \mathrm{q} 32$ translocations are frequently encountered in this disease. Interestingly, a 14q22-24 deletion occurred as single abnormality in 2 cases and as additional aberration in 1, resulting in a $16,6 \%$ incidence for this aberration. Only 3\% of the SMZL studies by Salido and coworkers [13] were found to carry $14 \mathrm{q}$ deletions, which showed a $1,5 \%$ overall incidence in a study of 3054 mature B-cell neoplasms [29]. The majority of cases with $14 \mathrm{q}$ deletion in the latter analysis were represented by atypical CLL cases having a therapy-demanding disease. Our 3 SMZLs with $14 \mathrm{q}$ deletion also had a therapy-demanding disease, requiring treatment after 1,8 , and 13 months from cytogenetic analysis.

One case in this study with a $\mathrm{t}(14 ; 19)(\mathrm{q} 32 ; \mathrm{q} 13)$ adds to a previous report of $4 / 330$ cases carrying this translocation [13]. The 14;19 translocation involving IgH and BCL3 is a rare aberration usually associated with a heterogeneous group of B-cell malignancies [30], including an atypical form of CLL with aggressive clinical features [31]. The identification of this subtle rearrangement may be difficult when banding quality is suboptimal, and it is possible that improved resolution obtained in ODN + IL2-stimulated cultures made the detection of this subtle rearrangement easier. In line with previous studies [32], our case had a rapidly progressive disease requiring treatment 3 months after diagnosis due to rapid lymphocyte doubling time.

In conclusion, we have shown that stimulation of mitosis with ODN + IL2 offers more mitotic figures of better quality and results in an increased rate of clonal aberrations in SMZL, in analogy with CLL. The profile of chromosome lesions obtained with this mitogen was in line with previous data, confirming that cytogenetic findings may be useful for the diagnosis of this lymphoid neoplasia. The detection of subtle rearrangements, such as $14 \mathrm{q}$ deletion and $14 ; 19$ translocations, might have been facilitated by improved banding resolution. Although more sensitive molecular genetic techniques using array $\mathrm{CGH}$ technology [33] may be of value for the detection of subtle unbalanced genetic lesions, this cytogenetic method may be ideal for prospective studied aiming at the definition of the prognostic impact of chromosome aberrations in SMZL.

\section{Acknowledgments}

This work was supported by MIUR PRIN, by Fondi Regionali ER, and by AIL-FE to A. Cuneo. L. Rizzotto is a fellow of AILFE A. Bardi and F. Cavazzini contributed equally. P. Musto and A. Cuneo shared senior authorship.

\section{References}

[1] S. H. Swerdlow, E. Campo, N. L. Harris et al., World Health Organization Classification of Tumours of Haematopoietic and Lymphoid Tissues, International Agency for Research on Cancer, Lyon, France, 2008.

[2] V. Franco, A. M. Florena, and E. Iannitto, "Splenic marginal zone lymphoma," Blood, vol. 101, no. 7, pp. 2464-2472, 2003.

[3] D. G. Oscier, E. Matutes, A. Gardiner et al., "Cytogenetic studies in splenic lymphoma with villous lymphocytes," British Journal of Haematology, vol. 85, no. 3, pp. 487-491, 1993.

[4] J. Dierlamm, L. Michaux, I. Wlodarska et al., "Trisomy 3 in marginal zone B-cell lymphoma: a study based on cytogenetic analysis and fluorescence in situ hybridization," British Journal of Haematology, vol. 93, no. 1, pp. 242-249, 1996.

[5] F. Solé, S. Woessner, L. Florensa et al., "Frequent involvement of chromosomes 1, 3, 7 and 8 in splenic marginal zone B-cell lymphoma," British Journal of Haematology, vol. 98, no. 2, pp. 446-449, 1997.

[6] F. Solé, M. Salido, B. Espinet et al., "Splenic marginal zone Bcell lymphomas: two cytogenetic subtypes, one with gain of $3 \mathrm{q}$ and the other with loss of 7q," Haematologica, vol. 86, no. 1, pp. 71-77, 2001.

[7] S. Gazzo, L. Baseggio, L. Coignet et al., "Cytogenetic and molecular delineation of a region of chromosome $3 \mathrm{q}$ commonly gained in marginal zone B-cell lymphoma," Haematologica, vol. 88, no. 1, pp. 31-38, 2003.

[8] A. Cuneo, R. Bigoni, M. G. Roberti et al., "Molecular cytogenetic characterization of marginal zone B-cell lymphonia: correlation with clinicopathologic findings in 14 cases," Haematologica, vol. 86, no. 1, pp. 64-70, 2001.

[9] X. Troussard, L. Mauvieux, I. Radford-Weiss et al., "Genetic analysis of splenic lymphoma with villous lymphocytes: a Groupe Francais d'Hematologie Cellulaire (GFHC) study," British Journal of Haematology, vol. 101, no. 4, pp. 712-721, 1998.

[10] J. M. Hernández, J. L. García, N. C. Gutiérrez et al., "Novel genomic imbalances in b-cell splenic marginal zone lymphomas revealed by comparative genomic hybridization and cytogenetics," American Journal of Pathology, vol. 158, no. 5, pp. 1843-1850, 2001.

[11] F. Vega, J. H. Cho-Vega, P. A. Lennon et al., "Splenic marginal zone lymphomas are characterized by loss of interstitial regions of chromosome $7 \mathrm{q}, 7 \mathrm{q} 31.32$ and $7 \mathrm{q} 36.2$ that include the protection of telomere 1 (POT1) and sonic hedgehog (SHH) genes," British Journal of Haematology, vol. 142, no. 2, pp. 216-226, 2008. 
[12] A. James Watkins, Y. Huang, H. Ye et al., "Splenic marginal zone lymphoma: characterization of $7 \mathrm{q}$ deletion and its value in diagnosis," Journal of Pathology, vol. 220, no. 4, pp. 461-474, 2010.

[13] M. Salido, C. Baró, D. Oscier et al., "Cytogenetic aberrations and their prognostic value in a series of 330 splenic marginal zone B-cell lymphomas: a multicenter study of the Splenic BCell Lymphoma Group," Blood, vol. 116, no. 9, pp. 1479-1488, 2010.

[14] F. Dicker, S. Schnittger, T. Haferlach, W. Kern, and C. Schoch, "Immunostimulatory oligonucleotide-induced metaphase cytogenetics detect chromosomal aberrations in $80 \%$ of CLL patients: a study of 132 CLL cases with correlation to FISH, $\mathrm{IgV}_{\mathrm{H}}$ status, and CD38 expression," Blood, vol. 108, no. 9, pp. 3152-3160, 2006.

[15] C. Haferlach, F. Dicker, S. Schnittger, W. Kern, and T. Haferlach, "Comprehensive genetic characterization of CLL: a study on 506 cases analysed with chromosome banding analysis, interphase FISH, $\operatorname{IgV}_{\mathrm{H}}$ status and immunophenotyping," Leukemia, vol. 21, no. 12, pp. 2442-2451, 2007.

[16] M. Mollejo, J. Menarguez, E. Lloret et al., "Splenic marginal zone lymphoma: a distinctive type of low-grade B-cell lymphoma: a clinicopathological study of 13 cases," American Journal of Surgical Pathology, vol. 19, no. 10, pp. 1146-1157, 1995.

[17] E. Matutes, D. Oscier, C. Montalban et al., "Splenic marginal zone lymphoma proposals for a revision of diagnostic, staging and therapeutic criteria," Leukemia, vol. 22, no. 3, pp. 487-495, 2008.

[18] G. L. Castoldi, F. Lanza, and A. Cuneo, "Cytogenetic aspects of B-cell chronic lymphocytic leukemia: their correlation with clinical stage and different polyclonal mitogens," Cancer Genetics and Cytogenetics, vol. 26, no. 1, pp. 75-84, 1987.

[19] D. E. Rooney, Human Cytogenetics: Malignancy and Acquired Abnormalities, Oxford university Press, 2001.

[20] M. F. Karger, "Guidelines for Cancer Cytogenetics: Supplement to an International System for Human Cytogenetics Nomenclature ISCN," Basel, Switzerland, 2005.

[21] J. M. Hernandez, C. Mecucci, A. Criel et al., "Cytogenetic analysis of B cell chronic lymphoid leukemias classified according to morphologic and immunophenotypic (FAB) criteria," Leukemia, vol. 9, no. 12, pp. 2140-2146, 1995.

[22] A. M. Gruszka-Westwood, R. A. Hamoudi, E. Matutes, E. Tuset, and D. Catovsky, "p53 abnormalities in splenic lymphoma with villous lymphocytes," Blood, vol. 97, no. 11, pp. 3552-3558, 2001.

[23] T. Zenz, H. Döhner, and S. Stilgenbauer, "Genetics and risk-stratified approach to therapy in chronic lymphocytic leukemia," Best Practice and Research, vol. 20, no. 3, pp. 439453, 2007.

[24] G. Juliusson, D. G. Oscier, M. Fitchett et al., "Prognostic subgroups in B-cell chronic lymphocytic leukemia defined by specific chromosomal abnormalities," New England Journal of Medicine, vol. 323, no. 11, pp. 720-724, 1990.

[25] C. Haferlach, F. Dicker, T. Weiss et al., "Toward a comprehensive prognostic scoring system in chronic lymphocytic leukemia based on a combination of genetic parameters," Genes Chromosomes and Cancer, vol. 49, no. 9, pp. 851-859, 2010.

[26] R. Buhmann, C. Kurzeder, J. Rehklau et al., "CD40L stimulation enhances the ability of conventional metaphase cytogenetics to detect chromosome aberrations in B-cell chronic lymphocytic leukaemia cells," British Journal of Haematology, vol. 118, no. 4, pp. 968-975, 2002.
[27] N. A. Heerema, J. C. Byrd, P. S. Dal Cin et al., "Stimulation of chronic lymphocytic leukemia cells with CpG oligodeoxynucleotide gives consistent karyotypic results among laboratories: a CLL Research Consortium (CRC) Study," Cancer Genetics and Cytogenetics, vol. 203, no. 2, pp. 134-140, 2010.

[28] A. Meloni-Ehrig, J. Meck, N. Christacos, J. Kelly, L. Matyakhina, and S. Schonberg, "Stimulation of B-cell mature malignancies with the CpG-oligonucleotide DSP30 and interleukin-2 for improved detection of chromosome abnormalities," Blood, vol. 114, 2009, ASH Annual Meeting Abstracts. Abs no. 1955.

[29] L. Reindl, U. Bacher, F. Dicker et al., "Biological and clinical characterization of recurrent $14 \mathrm{q}$ deletions in CLL and other mature B-cell neoplasms," British Journal of Haematology, vol. 151, no. 1, pp. 25-36, 2010.

[30] J. I. Martín-Subero, R. Ibbotson, W. Klapper et al., "A comprehensive genetic and histopathologic analysis identifies two subgroups of B-cell malignancies carrying a $\mathrm{t}(14 ; 19)(\mathrm{q} 32 ; \mathrm{q} 13)$ or variant BCL3-translocation," Leukemia, vol. 21, no. 7, pp. 1532-1544, 2007.

[31] Y. O. Huh, L. V. Abruzzo, G. Z. Rassidakis et al., "The $\mathrm{t}(14 ; 19)$ (q32; q13)-positive small B-cell leukaemia: a clinicopathologic and cytogenetic study of seven cases," British Journal of Haematology, vol. 136, no. 2, pp. 220-228, 2007.

[32] L. Michaux, J. Dierlamm, I. Wlodarska, V. Bours, H. Van Den Berghe, and A. Hagemeijer, " $t(14 ; 19) / B C L 3$ rearrangements in lymphoproliferative disorders: a review of 23 cases," Cancer Genetics and Cytogenetics, vol. 94, no. 1, pp. 36-43, 1997.

[33] C. Robledo, J. L. García, D. Caballero et al., "Array comparative genomic hybridization identifies genetic regions associated with outcome in aggressive diffuse large B-cell lymphomas," Cancer, vol. 115, no. 16, pp. 3728-3737, 2009. 


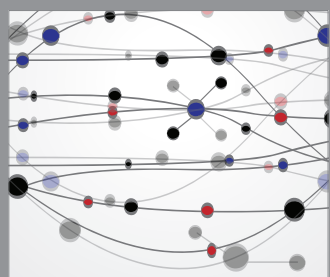

The Scientific World Journal
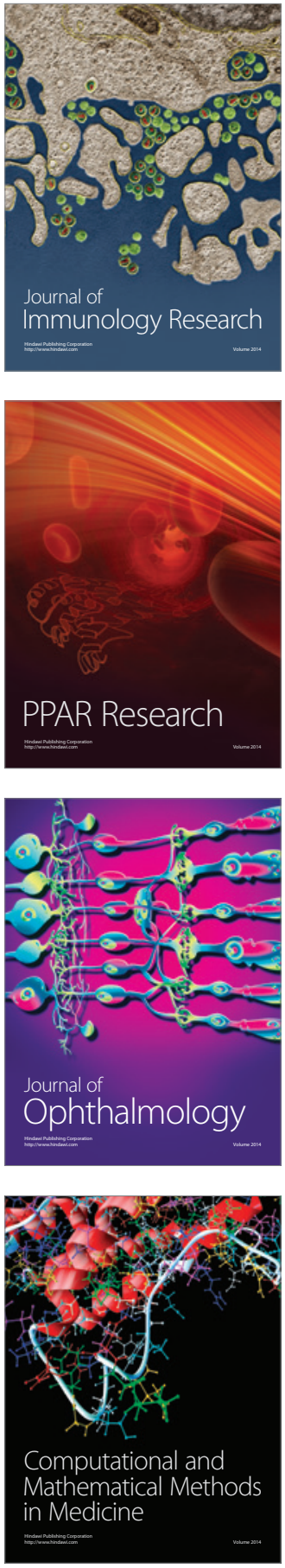

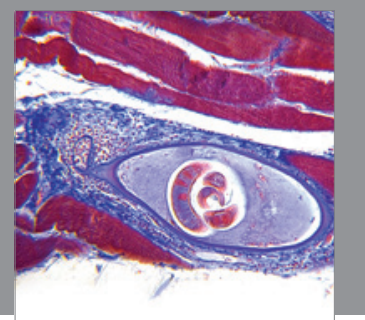

Gastroenterology

Research and Practice
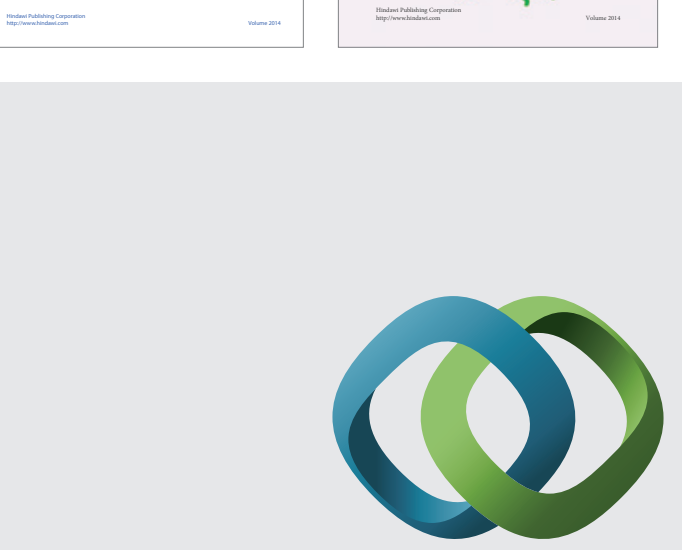

\section{Hindawi}

Submit your manuscripts at

http://www.hindawi.com
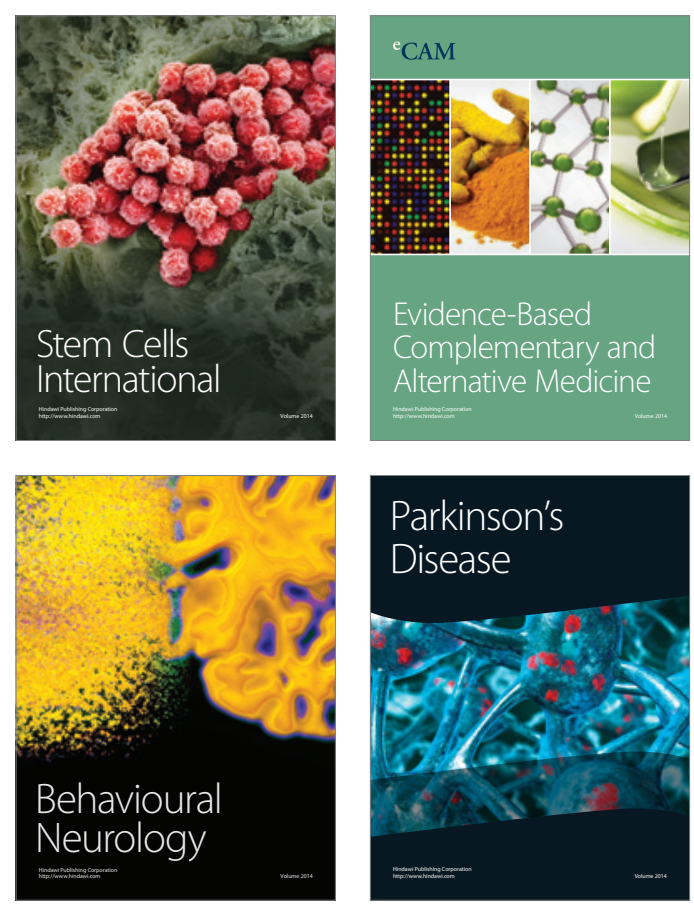

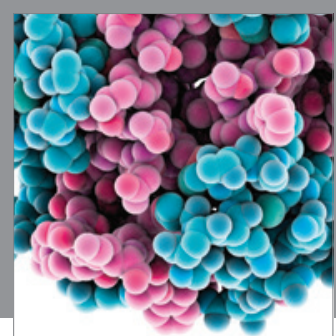

Journal of
Diabetes Research

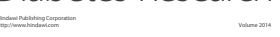

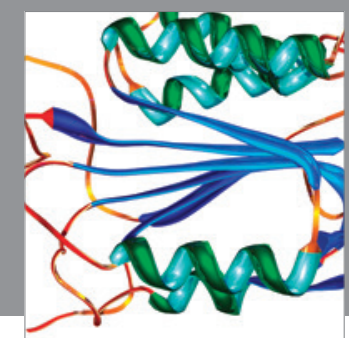

Disease Markers
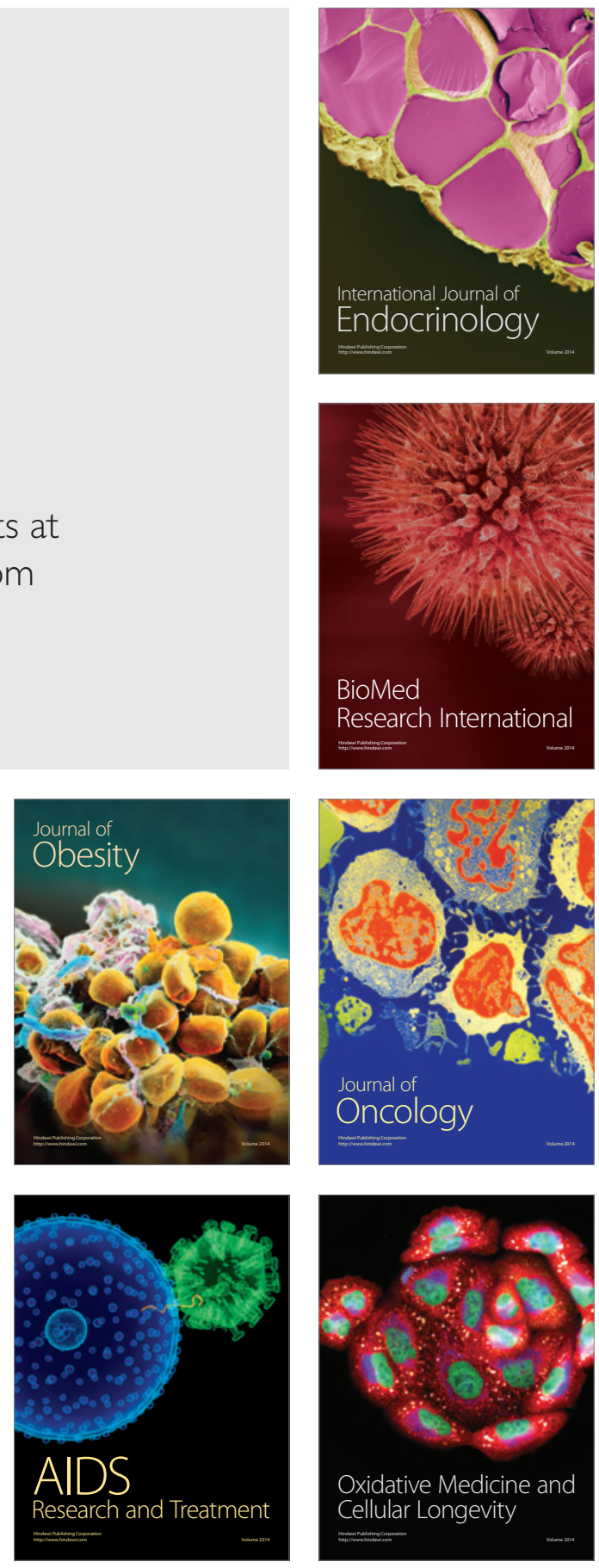